\title{
MI GENTE, MI MUNDO. Una reflexión antropo-educativa en voz alta sobre el conflicto escolar
} Juan Carlos ROMERO-VILLADÓNIGA Universidad de Huelva jucarovi66@gmail.com

\section{MY PEOPLE, MY WORLD. An anthropo-educational reflection aloud on schoolar conflict}

Resumen: En unos tiempos tan cambiantes, donde el valor se mide a partir de parámetros como el espacio, el tiempo o el acceso a información, los valores universales están perdiendo su actual preeminencia. En contextos desfavorecidos, la importancia del lugar y el sentido de pertenencia parten como elementos fundamentales en la construcción de la identidad del escolar. En estos contextos el espacio se conforma como un escenario donde se reflejan tensiones y oportunidades, donde se produce una lucha por la pervivencia de las identidades individuales y colectivas, y donde el multiculturalismo y la sustentabilidad de la comunidad son puestas a diario en riesgo debido a la existencia de múltiples anacronismos en el actual sistema educativo. El presente artículo gira alrededor de la importancia del respeto a la identidad individual y colectiva de las minorías como medio de solución de los actuales problemas de convivencia dentro y fuera del aula, si se desea una verdadera educación en valores.

Abstract: In this rapidly-moving period of change in which value is measured in terms of space, time or access to information, universal values are losing their current significance. In disadvantage contexts, important roles of the place and a sense of citizenship and belonging are highlighted as fundamental and essential aspects for enhancing self-identity in the student. Within this particular environment, space is conceived as a stage in which all tensions and opportunities are reflected, where a struggle for the survival of individual and colective identities is required, where multiculturalism and the sustainability of the community are daily placed at risk due to the existence of multiple anachronisms that inevitably exist in the present education system. This paper focuses on the relevance of respect for individual and colective identities of minorities as an effective way to address the ongoing problems of coexistence within and outside the classroom, if a true education in values is planned to be implemented.

Palabras clave: 


\section{El papel de la etnografía en nuestra investigación}

Vivimos en una sociedad de profundos cambios, donde el tiempo y el espacio han modificado sustancialmente valores y formas de entender la vida las cuales, en tiempos pasados, daban cohesión a nuestra sociedad. En este sentido, la cultura escolar no ha podido permanecer ajena a dichos cambios. Numerosos cambalaches en las normativas, formas diferentes de entender el hecho educativo, no son sino expresiones de la manifiesta debilidad del sistema formativo que no ha sabido, hoy por hoy, adaptarse a las nuevas necesidades tanto de padres como alumnos.

Cotidianamente escuchamos relatos acerca de conflictos y violencias dentro y fuera de nuestras aulas, y en un acto maniqueo exento de toda lógica, rápidamente intentamos y ponemos valor a los hechos, sin tener en cuenta las profundas variables que intervienen en cualquier hecho educativo.

Por esta razón, la etnografía escolar parte como elemento fundamental en nuestro análisis del quehacer diario. Cotidianamente se suele definir un como una etnografía realizada en el campo específico de la escuela. Numerosos autores han entrado en el capítulo de su definición (Woods 1987; Goetz y Lecompte 1988; Martínez rodríguez 1990; Aguirre Baztán 1995; Sanchís Ochoa y Cantón Delgado 1995; Sanmartín Arce 2000; Serra 2004, etc), aunque de todas las propuestas nos quedamos con la definición de Aguirre Baztan (1995: 3) el cual comenta que "la etnografía es el estudio descriptivo (graphos) de la cultura (ethos) de una comunidad”. Igualmente Serra (2004: 165) la define en los siguientes términos:

"El término etnografía se refiere al trabajo, el proceso o la forma de investigación que nos permite realizar un estudio descriptivo y un análisis teóricamente orientado de una cultura o de algunos aspectos concretos de una cultura y, por otra, han resultado final de este trabajo".

A partir de esta definición, podemos inferir las bases sobre las cuáles se debe postular la etnografía escolar, caracterizándose a partir de tres conceptos fundamentales:

a. Las estrategias utilizadas, las cuales proporcionan datos fenómenológicos, es decir representan la concepción del mundo de los participantes.

b. Las estrategias etnográficas de investigación empíricas y naturalistas. El recurrir a la observación participante y no participante permite la obtención de datos empíricos de primera mano los cuales son difíciles de obtener de no ser de esta forma.

c. La investigación en histórica se asocia básicamente al holismo ya que permite la descripción de fenómenos globales para poder determinar así las conexiones de causas y consecuencias que intervienen en la acción educativa.

Dicho de otra manera, el antropólogo no observa sino participando. En la observación participante el antropólogo interactúa con los sujetos de estudio debiendo vivir entre los puntos de la participación y la investigación, tal y como promueven Hammersley y Atkinson (2005: 130). El antropólogo forma parte de la acción observada, es un observador-observado que participa en el momento de forma voluntaria o involuntaria. Por esta razón no estamos de acuerdo con la posición de Freilich (1970), cuando argumenta que el etnógrafo no debe ser uno más en el grupo que estudia, al perderse los referentes, por tratarse de un enfoque básicamente emicista de la investigación. Consideramos que este argumento es bastante limitante en tanto en cuanto como apunta Carmelo Lisón (2010: 32): 
"Los objetos, las cosas, las acciones y los hechos tienen características empíricas, observables y descriptibles según el lenguaje de las cosas; se dan a conocer, se presentan y manifiestan, están delante de nosotros en locación circunscrita distinta de la que ocupan otros... y no sólo están ahí sino que se experiencia -se ven, se tocan, se oyen, se perciben realmente en primera persona, en observación consciente, de lo que da testimonio el observador participante, observador que tiene experiencia directa que constituyen la roca dura de la evidencia que soporta la explicación".

La proximidad del etnógrafo con el hecho estudiado permite, siempre y cuando se puede evitar en la medida de lo posible la subjetividad debida su cercanía, conocer aspectos los cuales forman parte de la dimensión oculta de la acción educativa, ya que entendemos que en el hecho educativo incide en tal cantidad de conexiones ocultas, como diría Capra (2003), que tan sólo asumiendo la necesidad de ser lo más aséptico posible al tiempo que convirtiéndose en agente participante de la acción, se puede llegar a un conocimiento complejo lo suficientemente representativo.

Efectivamente, el currículum oculto, es tan o más importante que el currículum programático de los centros educativos, pues mientras que en los segundos se parte de un conocimiento teórico y normativo cuyo único objetivo consiste en promover una cierta coherencia en el mundo educativo, el primero no es sino la realidad en la que la acción educativa se debe realizar día a día siendo, por tanto, el verdadero elemento conformador del hecho educativo al tomar como referencia el mundo real con las circunstancias del momento.

Coincidimos con Sanmartín Arce (2000: 139) cuando comenta que el investigador no es más que un reconstructor de la realidad, donde el extrañamiento derivado del concepto de Malinowski (1995) unido al principio de asombro, deben constituir sus pilares fundamentales. No obstante, debemos recordar que todos aquellos que hacen investigación en las escuelas han sido alumnos, en otros casos profesores, o bien han participado directamente en los órganos de gestión de los centros, de ahí que el extrañamiento o al principio de asombro no puedan darse en su plenitud para el caso de la etnografía escolar, ya que se trata de un campo bastante cercano a la cotidianidad del investigador.

\section{Aterrizando en el planeta "Marismas"}

El IES La Marisma se encuentra situado en pleno corazón del distrito V de Huelva. Cerca de la barriada Diego Sayago, uno de los principales puntos de vulnerabilidad no sólo de la provincia de Huelva sino de toda Andalucía Occidental, acoge en su seno a una gran cantidad de población proveniente de contextos culturales minoritarios con graves problemas de integración social.

Pasar por el barrio y observar las obras actuales de su arquitectura y urbanismo, nos hablan de subproductos espaciales marginales, con diversos estratos de formas de vida y con usos de los espacios, los cuales no son sino rememoraciones anquilosadas de viejas costumbres, de ritos y de simbologías las cuales hoy por hoy no tienen sentido de ser, pero que forman parte del imaginario de sus habitantes. Se trata de un lugar, una barriada de poco más de 20,000 personas, donde la etnia gitana cobra un papel protagonista, dándole forma, sentido y razón a innumerables peculiaridades urbanísticas y de ocupación del espacio las cuales sólo pueden ser entendibles si dejamos a un lado el etnocentrismo que imbuye a la actual sociedad onubense.

Debido quizás a su carácter desfavorecido, o por la propia composición social que le da vida, en el barrio no existen tan marcadamente definidos los universos de reconocimiento predominando por contra los de conocimiento, enunciados éstos como "un universo cerrado donde todo se constituye en sí mismo, conjuntos de códigos que algunos saben utilizar y 


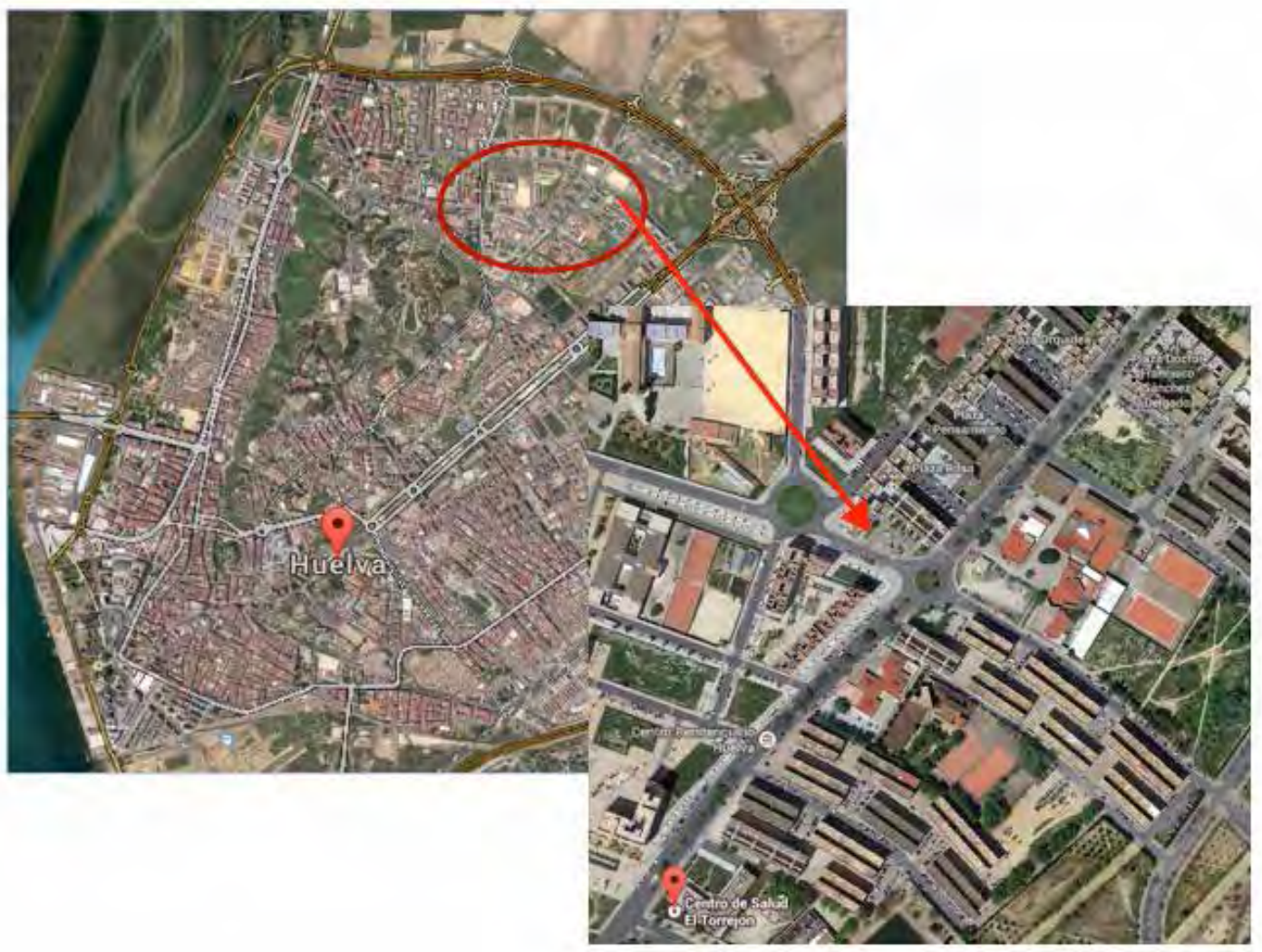

Imagen 1 y 2. Ubicación del IES en el contexto urbano onubense y disposición de la barriada Diego Sayago.

cuya clave poseen, pero cuya existencia todos admiten, totalidades parcialmente ficticias pero efectivas, cosmologías que podrían pensarse concebidas para hacer las delicias de los etnólogos" (Auge, 2008: 39).

Todo un universo simbólico concreto, con normas y formas de entender la vida arraigadas en el tiempo, el haber entrado en contacto con el actual modelo sobre-moderno, ha generado la concreción de nuevos elementos y valores en el seno de la comunidad, modificándolo y relativizando el universo hasta entonces presente. Los roles jugados hasta el momento, donde la familia era el principal organizador de la comunidad, no sólo a nivel de reglas y sentidos sino también espacial, se ha diluido en la vorágine de un mundo cada vez más globalizado y depredador de las comunidades más vulnerables. Ello generado una gran cantidad de tensiones y de incongruencias en el seno de la comunidad, reflejándose como no puede ser de otra manera en el campo educativo.

Todos esos cambios se han manifestado también en la apreciación del lugar, así como la conformación de la identidad de los integrantes de la barriada, generando graves conflictos inter-vecinales debido a la pérdida de unos valores los cuales sustentaban la solidaridad y la convivencia comunitaria, ya que, como apunta Auge (2008: 57):

"La organización del espacio y la constitución de lugares son, en el interior de un mismo grupo social, una de las apuestas y una de las modalidades de las prácticas colectivas e individuales. Las colectividades, como los individuos que se incorporan a ellas, tienen necesidad simultáneamente de pensar la identidad y la relación y, para hacerlo, de simbolizar los constituyentes de la 
identidad compartida (por el conjunto de un grupo), del identidad particular (de tal grupo o de tal individuo con respecto a los otros) y de la identidad singular del individuo o del grupo de individuos (en tanto no son semejantes a ningún otro)".

Los problemas que se generan en el centro no son sino el reflejo de las tensiones, las oportunidades, los deseos y frustraciones de una juventud marcada por la vulnerabilidad y por la necesidad de autoafirmación dentro del contexto de la sociedad onubense. Al igual que todos los del actual sistema educativo español, a pesar de gozar de autonomía pedagógica, se encuentra inserto dentro de la lógica social en la que predomina un componente unilineal- cartesiano -mecanicista. Este anacronismo que no es fruto de la política del IES, sino de la lógica racional de este mundo macdonalizado (Ritzer, 2002), provoca la existencia de múltiples incoherencias dentro y fuera del aula. Como apunta Francisco Miranda López (2006: 2):

"la existencia de estos anacronismos plantea la necesidad -más allá de organismos y retóricas -de una nueva revolución educativa que no sólo debe atender la escolarización de masas, sino subjetividades más contradictorias y dispersas, socialmente diferenciadas y con expectativas y sentidos de mayor diversidad, todo ello en el marco de una sociedad de información y del conocimiento que con o sin intención, desde escolarizar el pacto, penetra con otros códigos, las inteligencias, las conciencias y las emociones, con el consecuente efecto de la banalización trivialización y su profesionalización de los agentes y dispositivos escolare".

La escuela del hoy por hoy, no es capaz de establecer puentes entre la cultura juvenil y la cultura escolar. La incapacidad de enfrentarse y de adaptarse a la sobremodernidad, con ritmos de tiempo, espacios y un triunfo del individualismo frente al espíritu colectivo, hace que la brecha entre lo que la educación ofrece y el individuo reclame sea cada vez más grande, siendo fuente de frustración tanto para unos como para otros, manifestándose en aspectos como el abandono escolar, la violencia dentro y fuera de las aulas, la falta de perspectiva

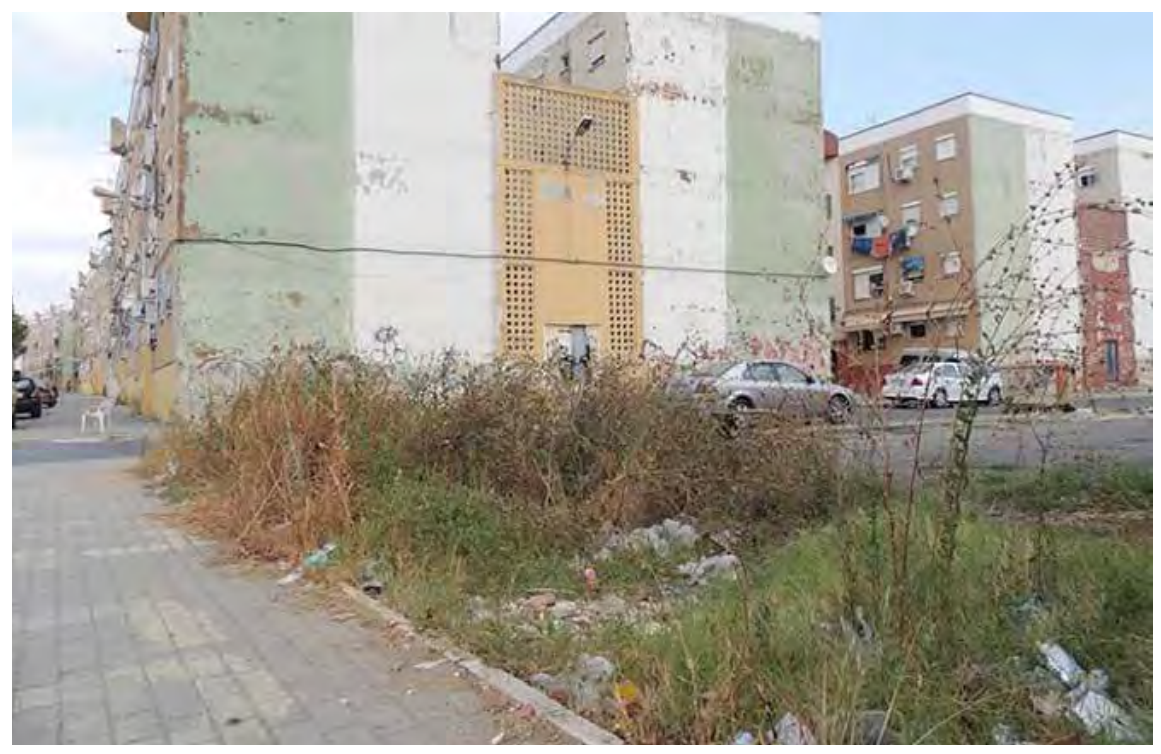

Imagen 3. Vista proximal del barrio desde las traseras del IES. 
o el paulatino e inexorable descenso de los rendimientos escolares ante la falta generalizada de motivación tanto por parte de profesores, como alumnos y familias en general.

Con una población de etnia gitana de aproximadamente el $80 \%$ del alumnado en ESO, así como también población proveniente de otras culturas o de otras situaciones sociales donde el riesgo de exclusión es más que manifiesto, el vacío que genera la escuela frente a las necesidades y expectativas de inserción social de este colectivo se hace cada vez más evidente.

Aprendizajes poco significativos, adaptados en eso sí a la dinámica del centro así como los niveles de competencia curricular del alumnado, no son sino formas encubiertas de evidenciar el conflicto escolar, ya que el alumnado no lo concibe como parte de su entorno y un lugar vivencial, sino como un centro disciplinario y regulatorio que castiga y castra su propia idiosincrasia. Y no se encuentra exento de razón, pues hoy por hoy, el desfase existente entre lo que el sistema educativo ofrece y la sociedad demanda, en especial el colectivo adolescente, es cada vez más acusado, encontrándonos con un sistema educativo alejado de los centros de interés y expectativas vitales de sus principales beneficiarios, con la consabida frustración para todos los que participan en el hecho educativo.

\section{Contra el mundo escolar}

Que la escuela actual es percibida un centro disciplinario y regulatorio que castiga y castra, en los términos expuestos en su día por Foucault (2000), es algo más que evidente. Expresiones como "esto es una cárcel", "los profesores no son más que carceleros", no son sino reflejo de la opinión que tiene la sociedad civil respecto de la institución. Resulta frecuente escuchar relatos por parte del alumnado, en los cuales se mezcla por un lado su frustración hacia el entorno social en el que se desarrollan, con su falta de expectativas y la más que notoria ausencia de normas por parte de los agentes externos al hecho educativo, entiéndase familias o la propia comunidad en general. Tal es el caso de Antonio, mestizo de padre gitano y madre paya, cuando comenta:

Todos los días me meto en problemas en el insti, no me dejan ni respirar, cada vez que levantó la cara tengo siempre a un profesor delante mía que me corrige y casi sin pedirle explicaciones me deriva al aula de guardia, donde ya soy bastante conocido. No entiendo por qué tiene que haber tantas normas, las cuales ni comprendo, y si mis padres no me ponen a mí esas normas, ¿quiénes son estos payos para decirme lo que debo o no de hacer?. Pues sabes lo que te digo, que aquí ellos mandan, pero en el barrio es cosa bien distinta, allí la ley es otra (Antonio, 4/12/2014).

Así, entre dos mundos bien distintos, el normativo férreo del centro y el laxo de la calle, el adolescente tiene desarrollar su vida cotidiana. Inmerso en valores y contravalores, no sabe en ocasiones discernir que está bien y que está mal, pues la pérdida de sentidos a los que se ha visto sometida su comunidad, ha desarticulado todo su entramado social, primando el valor individual frente a la importante colectividad, uno de los principales referentes que conforman el sentir y la identidad del pueblo gitano.

Igualmente, frente a modelos pasados considerados hoy por hoy obsoletos, el triunfo de la tecnologización en las aulas ha propiciado un aumento del individualismo frente al espíritu colectivo y comunitario de tiempos pasados. Los trabajos de equipo han sido sustituidos por unidades portátiles las cuales sumergen al alumno dentro del universo virtual de la información, perdiendo la referencia de sus iguales al primar más el trabajo individual que el grupal. 
Ello genera un estado de deshumanización al romperse el tradicional diálogo entre iguales, para ser el frío mundo de los códigos binarios los que ocupen ese lugar. Ésa pérdida del espíritu comunitario genera entre otros aspectos, una potenciación de la competitividad y una pérdida de la empatía por parte del alumnado, al hacerse el proceso más mecánico, debido a la pérdida de la comunicación y, con ella, de los sentimientos y relaciones que se establecen en estas actividades entre los iguales. Este aspecto, muy denunciado por autores como Bellamy $(2015,2016$, tiene su reflejo en múltiples observaciones recogidas durante el proceso etnográfico, destacándose a modo de ejemplo, la de Maite:

Yo prefiero trabajar sola, así no me dan la murga ni me distraen de mis ocupaciones. Cuando voy a hacer algo en equipo para mí es un suplicio, porque al final todos hablan mientras yo trabajo, y eso no me parece nada justo porque si yo me esfuerzo los demás también. Por eso, cuando hacemos trabajos por el ordenador, yo paso de todos y me meto en lo mío, me de igual lo que digan o hagan, porque al final la que voy a aprobar soy yo y no ellos, y no me importa lo que les ocurra (Maite, 13/I/2015).

Esta concepción en la cual el individuo gana a la comunidad resulta más frecuente de lo que parece, siendo prueba evidente del triunfo de la sobremodernidad augeriana sobre los valores que deben conformar una auténtica filosofía de la educación. Pero este tipo de relaciones también se refleja a la hora de analizar las conexiones interpersonales entre el profesorado y el alumnado, existiendo dos universos simbólicos de muy marcada divergencia, siendo del diálogo más un monólogo castrador que un verdadero debate en sí.

El valor del profesor nunca es cuestionado el actual sistema educativo, quedando siempre en un segundo plano las inquietudes y el mundo del adolescente. Unas veces de forma paternalista, otras impositivas, el profesor adoctrina y somete a juicio el imaginario del alumno, en un intento de configurar una identidad más próxima a lo que se pide en la sociedad actual. No obstante, como apunta Achilli (1996: 630): "el niño construye auto imágenes que influyen en los procesos de aprendizaje y en el desenvolvimiento de su vida escolar. Va configurando lo que hemos denominado identidades escolarizadas", de ahí la enorme responsabilidad del educador, pues de una correcta intervención depende una óptima socialización del individuo.

Esta intromisión de la experiencia escolar nunca es aséptica, sino que está influenciada por multitud de variables, desde la propia ideología particular del profesorado, el cual en no pocas ocasiones es visto como el "enemigo" (Wolcott, 2010), pasando por las intencionalidades programáticas de la institución o del entorno sociopolítico en el cual se desarrolla el hecho educativo, siendo esto una gran rémora en la conformación de identidades libres y plenamente asumidas, de ahí que en innumerables casos se provoque una enorme frustración tanto en el profesorado, que se ve impotente de imponer un criterio no pocas veces erróneos, como sobre todo de un alumnado que ya de por sí se enfrenta a graves problemas de conformación de su identidad debido al entorno en el que ha tocado vivir, como se puede comprobar en múltiples relatos recogidos a lo largo de cerca de siete años de investigación paciente concienzuda en el IES:

Para qué voy hablar ni decir nada, si no me comprenden. Cada vez que abre la boca siempre hay un profe que me dice que eso está mal, que no sé hacer las cosas, que le haga caso únicamente a él porque aún no tengo edad de entenderlas. Pero si yo ni las entiendo, ni tampoco me las hacen entender, ¿por qué tengo que hacerles caso?, ¿Acaso yo no tengo también en ocasiones razón?. Al final haré lo que yo quiera y como yo quiera, mientras mis padres no me regañen ni se enteren no habrá problemas (Israel, 11/2/2015 ). 


\section{Mi cuerpo, mi mundo}

La existencia de un sistema educativo tan lleno de tensiones y ambigüedades, tiene su reflejo en el propio cuerpo del adolescente. Resulta normal, en una etapa en la cual la conformación de la identidad es más importante, que el adolescente adopte roles y estéticas las cuales se asemejen a un grupo de iguales, aunque en principio parezca una contradicción con respecto al triunfo del individualismo que hemos comentado con anterioridad.

La globalización afecta de lleno a un alumnado el cual, por un lado manifiesta su deseo de mantener su identidad como etnia, pero que se deja llevar por los gustos y las estéticas del mercado, generando una cultura híbrida en todos sus sentidos (García-Canclini, 2001). Ello hace que entren una contradicción consigo mismo la cual genera tensión intra-personal, al tiempo que con respecto al resto de iguales.

Por medio de tatuajes o de otras simbologías, el alumno marca territorio dentro del propio espacio educativo, fragmentando el concepto unitario con el que inicialmente se concibe, haciendo que la diversidad forme parte del lenguaje cotidiano del Centro. Diversidad no sólo en lo referente a contenidos y currículum se refiere, sino también a las normas de enfocarse y enfrentarse ante situaciones y conflictos cotidianos, pues la pertenencia a un clan u otro, añaden un plus de dificultad por la existencia de rivalidades y rencillas entre familias, convirtiéndose así el centro educativo en un escenario de lucha de poder por parte del alumnado.

Y es que como apunta Muntañola y Domínguez (1992), las formas en que se accede al espacio, se construye, se estructura, se ocupa y se habita, están directamente vinculadas a las relaciones sociales que rigen y definen el acceso ocupación y habitación.

El sentido de pertenencia está por encima, en este caso, a las normas de convivencia y las reglas del juego. Ya hemos apuntado que la escuela actual no genera comunidad, sino más bien todo lo contrario, un espacio de resistencia en el cual las contradicciones provocan tensiones y un profundo desasosiego entre todos los agentes educativos, ya sea profesionales, familias o alumnos.

El contexto en el cual se desarrolla la acción educativa genera por un lado una deconstrucción de la identidad individual del alumno, al tiempo que paradójicamente, un reforzamiento del mismo en dirección a lo que es su conjunto familiar y clánico, en un fenómeno denominado por Pietro Scarduelli (2005: 67) "Neo-Tribalismo", es decir, como respuesta a la inmensa soledad del ser humano actual, el reforzamiento de este sentido de pertenencia, aunque sea en algunos aspectos sólo, permite al adolescente encontrar puntos de referencia frente a sus iguales, pudiendo aplicarse dicho concepto tanto a las sociedades inmigrantes como hizo el autor, así como a las minorías étnicas, caso de la gitana.

\section{Lugares para la coerción}

El conflicto también se puede hacer presente a la hora de analizar las formas de uso del espacio que se dan en las prácticas cotidianas del alumnado. La existencia de relaciones entre el espacio físico y simbólico genera lugares donde ciertas prácticas sociales se consideran como legítimas, todas ellas encaminadas a la construcción y afirmación del poder.

Esta reificación se manifiesta en ritos tales como la asignación de un espacio impuesto por parte del alumnado, en una clara pugna contra el orden establecido. Sentarse en lugares diferentes a los marcados por el profesorado no son sino una forma de pujar por el poder dentro del aula, siendo causa de innumerables conflictos los cuales son difícilmente resueltos debido al espíritu desafiante del alumnado, en una clara muestra de fuerza no sólo frente a sus iguales, sino también hacia el resto de los miembros de la comunidad.

Igualmente resulta más que notoria la enorme influencia que acude al espacio en las relaciones entre iguales. Así, sentarse al lado de las estufas, o próximo a las ventanas como lo hace sino evidenciar la existencia de una profunda jerarquía del espacio, marca ritmos y 
sobre todo relaciones sociales, todo un entramado simbólico donde el poder del espacio es signo de identidad.

La ocupación física del espacio y su significado social, tal y como podría apuntar autores como Bordieu (1999), se pueden hacer también objetivizar en situaciones sociales percibidas tales como la posición del cuerpo o los usos del lenguaje, por citar algunas formas de la expresión social de las relaciones. Efectivamente, cuando el espacio es amenazado y se pone en riesgo su poder, todo vale, con tal de mantener la preeminencia entre sus iguales.

Así, el levantamiento de las manos de forma abrupta, el arqueamiento corporal o el dejarse caer sobre la mesa, no son sino formas encubiertas de violencia, tanto entre iguales, y el resto de los miembros de la comunidad educativa, siendo una forma velada o explícita según se mire de desafío y cuestionamiento del poder establecido.

Estas manifestaciones no son sino una manera de transmitir mensajes por parte del alumnado, aprovechando el espacio, pudiendo ser interpretados como maneras de ocupar el ámbito escolar de forma alternativa a lo que marca la norma colectiva, dotándola de nuevos significados.

\section{Hacia una verdadera educación en valores}

Como expone Petra María Pérez Alonso (2005: 148): "la estructura simbólico moral de un grupo social se asienta sobre bases que constituyen un marco común de referencia, y es papel de la educación ocuparse de la transmisión cultural de ese marco de referencia a los más jóvenes".

El actual sistema educativo presenta graves deficiencias las cuales se ha manifestado en aspectos como la persistencia del fracaso escolar, especialmente en colectivos vulnerables (Río, 2011), con una acusada ruptura generacional entre todos los agentes educativos.

Las causas que explican estos cambios pueden ser múltiples, como hemos explicado en apartados anteriores. La sobremodernidad a la que siempre hace referencia Auge (2008), no es sino la punta del iceberg, "la premodernidad de la sobremodernidad". La velocidad del cambio de los saberes, la liquidez en la que se ve inmerso el sujeto especialmente cuando incide en él la condición de vulnerabilidad (Bauman, 2006) el abandono educacional (tanto de conocimientos como sobre todo de emociones y valores) de las familias para con los hijos, la existencia de un sistema educativo absorto en el plano teórico y lejos de la actual realidad del mundo, no son sino problemas añadidos los cuales se agravan día a día por la enorme y desleal competencia de agentes socializadores como internet o la televisión.

Tan sólo basta dar un paseo, un zapeo por los diferentes canales que constituyen el mundo de la caja tonta, para darnos cuenta del enorme peligro que suponen estos agentes de socialización indirecta en la conformación del adolescente. Contravalores reforzados a golpe de saraos, pérdida de elementos básicos en el diálogo como la escucha, el turno de palabra, el debate consensuado, las reglas del juego, jtodo brilla por su ausencia!

Desde siempre se ha dicho que el educador es como un agricultor, a partir de lo que siembre así nace. Sin embargo, para realizar esta reflexión debemos tener también en cuenta, que para la recogida de una buena cosecha influyen muchos y variados elementos tales como el agua, las temperaturas, la dirección de los vientos, por la composición de la tierra. Y para el caso de la educación no es menos.

Ello no quiere decir que desde el actual sistema educativo no se esté educando en valores, pero es importante reflejar que una cosa son los valores que queremos exponer, y otra la realidad en la cual educamos. Existe un gran desajuste entre lo ideal y lo real, así como un abismo entre las familias y la escuela (Abbey, 2004; Poveda, 2001). Creemos que simplemente trasmitiendo la idea seremos capaces de generar la creencia.

Como bien decía Antonio Machado, "caminante no hay camino, se hace camino al andar", y ese es precisamente uno de los principales déficits del actual sistema educativo 
español, ya que de nada sirve hablar de valores si no somos capaces de darle una figuración concreta, es decir si no somos capaces de darle forma física por medio de situaciones reales.

Malinowski (1995) hablaba de la disparidad existente entre la cultura ideal y la real. Así, para el caso que nos ocupa, se puede tener un sistema de valores concretos, pero a la hora de su representación material éstos pueden variar drásticamente a partir de la confluencia de diferentes factores. Por esta razón no es lo mismo hablar de un valor narrado que de un valor real. Y, en ese sentido, el profesorado debe jugar un papel fundamental, pues aunque en el subconsciente colectivo exista la idea que se ha perdido el control de la situación y del gobierno en las aulas, a pesar de sentirse en un porcentaje elevado con una gran frustración la cual no sólo profesional sino también personal, deben jugar un papel fundamental por medio de la acción, por medio del saber estar.

Los valores encarnan todo una configuración del bien, y son motivo de solidaridad y unión del colectivo. Libertad, Solidaridad, Respeto, no son palabras vacías que se encuentren en la retórica de la filosofía o de la ética, sino que son creencias morales las cuales permiten la supervivencia de la comunidad. Son imaginarios colectivos siempre inacabados y en constante proceso de formación, adaptados a las necesidades y circunstancias que en esos momentos tocan vivir, y que se modifican en su significado según la época en cuestión. Pero al mismo tiempo son verdades sobre las cuales se funda una sociedad y sobre las que el educador debe incidir por medio de la praxis.

Enseñar no consiste únicamente en trasmitir conocimientos, sino debe ser, ante todo, un modo de pensar, un estilo de vida. El educador debe ser un referente que ofrezca testimonio al resto de la comunidad en pro de una potenciación de los valores que le dan sentido tanto al hecho educativo, como a la pertenencia en sociedad (Del Toro, 2012).

Educar supone asumir la existencia de un currículum oculto el cual es siempre mucho más importante que el oficial o el que teóricamente se imponga desde la Administración, y tan sólo desde el momento que se asuma como parte del hecho educativo, quizás a partir de entonces y sólo quizás, podamos educar verdaderamente en valores.

Y es que, concluyendo, como diría Paulo Freire (2002: 24) "Enseñar no es transferir conocimiento, sino crear las posibilidades de su producción o de su construcción... Quien enseña, aprende al enseñar y quien aprende enseña al aprender", quizás esa sea la clave de la educación del futuro si realmente se desea construir sujetos libres y en libertad.

\section{Bibliografía}

ABBEY, S.

2004 Las barreras sistémicas entre el hogar y la escuela, en ROSS, J. y WATKINSON, A. (ed), La violencia en el sistema educativo. Madrid: La Muralla.

ACHILLI, E.

1996 Práctica docente y diversidad socio-cultural. Rosario: Homo Sapiens.

Aguirre Baztán, a. (Ed.)

1995 Etnografía. Metodología cualitativa en la investigación sociocultural. Barcelona: Mar-

AUGÉ, M combo.

2008 Los no lugares. Espacios del anonimato. Barcelona: Gedisa Editorial.

BAUMAN, Z.

2006 Confianza y temor en la ciudad. Vivir con extranjeros. Barcelona: Arcadia.

BELLAMY, F. X.

2015 Pourquoi enseignons-nous?. Clermont-Ferrand: SOS Education.

2016 Les déshérités ou l'urgence de transmettre. Paris: Plon.

BOURDIEU, P.

1999 El efecto de lugar. En La miseria del mundo. FCE: México.

CAPRA, F.

2003 Las conexiones ocultas. Barcelona: Anagrama. 
DEL TORO, J. M.

2012 Educar con co-razón. Bilbao: Desclée

FOUCAULT, $\mathrm{M}$.

2000 Vigilar y castigar. Buenos Aires: Siglo XXI.

FREILICH, M.

1970 Marginal natives: Anthropologist at work. Nueva Cork: Harper \& Row.

FREIRE, P

2002 Pedagogía de la autonomía. México: Siglo XXI.

GARCÍA- CANCLINI, N.

2001 Culturas híbridas: estrategias para entrar y salir de la modernidad. Madrid: Paidós

GOETZ, J.P. \& LECOMPTE, M.D.

1988 Etnografía y diseño cualitativo en investigación educativa. Madrid: Morata.

HAMMERSLEY, M. y ATKINSON, P.

2005 Etnografía. Métodos de investigación. Barcelona: Paidós.

LISÓN TOLOSANA, C.

2005 Antropología, Horizontes educativos. Granada: Editorial Universidad de Granada.

2010 Antropología integral. Ensayos Teóricos. Madrid: Editorial Universitaria Ramón Areces.

2014 Antropología, Horizontes simbólicos. Valencia: Tirant Humanidades.Scarduelli, P (2005). Per un antropologia del XXI secolo. Nápoles: Squilibri.

MALINOWSKI, B.

1995 Los argonautas del Pacífico Occidental. Barcelona: Península.

MARTÍNEZ, J.B.

1990 Hacia un enfoque interpretativo de la enseñanza: etnografía y curriculum. Granada: Servicio de Publicaciones de la Universidad de Granada.

MIRANDA, F.

2006 El efecto de lugar sobre la construcción de la identidad escolar. En IX Simposio Interamericano de Investigación Etnográfica en Educación. México.

MUNTAÑOLA, J. y DOMÍNGUEZ, M.

1992 Descubrir el medio urbano. Barcelona, la arquitectura de una ciudad, y la opinión de los niños. Instituto de Ecología Urbana de Barcelona: Barcelona, España.

OSORIO, F.

2006 Violencia en las escuelas, un análisis desde la subjetividad. Buenos Aires: Noveduc.

PÓVEDA, D.

2001 La educación de las minorías étnicas desde el marco de las continuidades-discontinuida-

RIO, M. Á. des familia-escuela. Gazeta de Antropología, 17, 31.

2011 Más allá del protocolo: Estrategias contra el absentismo en centros andaluces de atención

RITZER, G educativa preferente. Revista Témpora, 14, 39-63.

2002 La macdonalización de la sociedad. Un análisis de la racionalización en la vida cotidiana. Barcelona: Ariel Sociedad Económica.

SANCHIZ, P. \& CANTÓN, M.

1995 Acceso y adaptación al campo. En Aguirre Baztán, A. (Ed.) Etnografía. Metodología cualitativa en la investigación sociocultural. Barcelona: Marcombo.

\section{SANMARTÍN, R.}

2000 Etnografía de los valores. Revista Teoría de la educación, 12, 129-141.

SERRA, C.

2004 Etnografía escolar, etnografía de la educación. Revista de Educación, 334, 165-176.

WOLCOTT, $\mathrm{H}$.

2010 El maestro como enemigo. En Velasco, H., García, F.J. y Díaz, A. (Ed), Lecturas de AntroWOODS, P. pología para Educadores. Madrid: Trotta.

1987 La escuela por dentro. La etnografía en la investigación educativa. Barcelona: PaidósMEC. 